\title{
AÇÕES COLABORATIVAS EM AMBIENTES VIRTUAIS DE APRENDIZAGEM: UMA REFLEXÃO SOBRE A FORMAÇÃO CONTINUADA DE TUTORES.
}

\author{
João Carlos Rossi ${ }^{1}$
}

\begin{abstract}
RESUMO
É sabido que a Educação a Distância (doravante, EaD) vem crescendo significativamente ao longo dos anos, favorecendo a democratização do ensino em tempos e espaços diferentes. Desse modo, tendo em vista a preocupação com essa modalidade de ensino, deve-se garantir a formação continuada de todos os sujeitos envolvidos nesse processo. À vista disso, a partir de reflexões realizadas, definiu-se como objetivo deste artigo, refletir sobre a formação continuada de tutores, uma vez que a atividade de tutoria requer do profissional, mediação colaborativa do conhecimento em ambientes virtuais de aprendizagem. Para atender ao proposto, ancorou-se o estudo bibliográfico em autores como Alarcão (1998), Costa-Hübes (2008), Esteves e Rodrigues (1993), Magalhães (2004), Demo (1998), dentre outros, a fim de aquecer as discussões e fundamentá-las. A partir das pesquisas, fica evidente que a formação continuada é uma prática necessária para tutoria, uma vez que subsidia o profissional a mediar o processo de aprendizado do aluno, de forma critica e colaborativa, por meio do suporte online.
\end{abstract}

Palavras-chave: Tutor. Formação Continuada. Ambientes Virtuais de Aprendizagem. Ensino a Distância. Tutoria.

\footnotetext{
${ }^{1}$ Especialista em Educação Especial e em Educação a Distância com ênfase na formação de tutores. Mestrando em Letras, no Programa de Pós-graduação Stricto Sensu em Letras, pela Universidade Estadual do Oeste do Paraná - UNIOESTE Campus Cascavel. Professor do Centro de Ensino Superior de Realeza - CESREAL.
} 
COLLABORATIVE ACTIONS IN VIRTUAL LEARNING ENVIRONMENTS: A REFLECTION ON THE CONTINUED TRAINING OF GUARDIANS.

\begin{abstract}
It is known that Distance Education (hereinafter, Distance Education) has been growing significantly over the years, favoring the democratization of education in different times and spaces. Thus, in view of the concern with this modality of education, it is necessary to guarantee the continuous formation of all the subjects involved in this process. In view of this, based on the reflections, it was defined as the objective of this article, to reflect on the continuous training of tutors, since the activity of tutoring requires the professional, collaborative mediation of knowledge in virtual learning environments. In order to meet the proposal, the bibliographic study was anchored in authors such as Alarcão (1998), Costa-Hübes (2008), Esteves and Rodrigues (1993), Magalhães (2004), Demo (1998), among others, the discussions and justify them. From the researches, it is evident that the continuous training is a necessary practice for tutoring, since it subsidizes the professional to mediate the learning process of the student, in a critical and collaborative way, through the online support.
\end{abstract}

Keywords: Tutor. Continuing Education. Virtual Learning Environments. Distance learning. Mentoring.

\title{
INTRODUÇÃO
}

Sabe-se que a Educação a Distância (doravante, EaD) foi normatizada enquanto modalidade educacional a partir do Decreto 5.622, de 19 de dezembro de 2005, revogado pelo Decreto $\mathrm{n}^{\circ}$ 9.057, de 25 de maio de 2017, o qual regulamenta o artigo 80 da Lei $\mathrm{n}^{\circ}$ 9394, de 20 de dezembro de 1996, que estabelece diretrizes e bases para a educação brasileira.

De acordo com o decreto $\mathrm{n}^{\circ} 9.057$,

ART. $1^{\circ}[\ldots]$ considera-se educação à distância a modalidade educacional na qual a
mediação didático-pedagógica nos processos de ensino e aprendizagem ocorra com
a utilização de meios e tecnologias de informação e comunicação, com pessoal
qualificado, com políticas de acesso, com acompanhamento e avaliações
compatíveis, entre outros, e desenvolva atividades educativas por estudantes e
profissionais da educação que estejam em lugares e tempos diversos (BRASIL, 
Vol.11 - №19 - JANEIRO - 2019 - ISSN: 1982-6109

2017).

Esse documento define e institucionaliza o que se compreende por $\mathrm{EaD}$, nesta modalidade, mediada pelo uso de recursos tecnológicos, as atividades de ensino-aprendizagem ocorrem em tempos e espaços distintos. Foi pensando nisso que, definiu-se como objetivo de pesquisa refletir sobre a formação continuada de tutores, para mediação colaborativa do conhecimento, em espaços virtuais de aprendizagem.

A partir desse recorte, delimitou-se como objetivos específicos,

$\checkmark \quad$ Mostrar a formação continuada do professor tutor como uma prática necessária para o exercício de tutoria;

$\checkmark \quad$ Entender o processo de tutoria como um espaço de colaboração;

$\checkmark \quad$ Pensar acerca da mediação pedagógica em ambientes virtuais de aprendizagem em uma perspectiva colaborativa.

À vista dos objetivos traçados, recorreu-se aos pressupostos teóricos metodológicos da pesquisa bibliográfica, uma vez que o problema de pesquisa será refletido por meio de leituras de artigos científicos, teses e dissertações, livros e demais documentos que contribuam para as reflexões em análise.

Essa pesquisa se mostra de extrema relevância, uma vez que, o profissional, independente da área de atuação, após passar pelo processo de formação inicial deve a compreender como contínua e ininterrupta. Em se tratando de $\mathrm{EaD}$, no caso desta pesquisa, é basilar que o tutor esteja devidamente formado tendo em vista a complexidade desta modalidade de ensino, uma vez que se tratar de tempos e espaços diferentes do ensino presencial.

Ao verificar a existência de várias pesquisas travando diálogo com a formação continuada de tutores presenciais e a distância, identificou-se que, embora tenha estudos expressivos tratando sobre o assunto, ainda hoje o ensino à distância em uma perspectiva colaborativa é um desafio, haja vista a necessidade de se ter profissionais com formação especifica para o trabalho de tutoria sob essa perspectiva.

A partir do exposto, esse artigo foi organizado da seguinte forma: a introdução; na seção 1; apresentar-se-á a formação continuada de tutores online como uma prática necessária; 
Vol.11 - №19 - JANEIRO - 2019 - ISSN: 1982-6109

na seção 2, o papel do tutor como professor colaborador virtual; na seção 3, a mediação pedagógica em ambientes virtuais de aprendizagem; seguido das considerações finais e referências.

\section{A FORMAÇÃO CONTINUADA DE TUTORES: UMA PRÁTICA NECESSÁRIA}

A Formação Continuada (FC, ora em diante), apresenta-se como uma prática necessária para os profissionais de todas as áreas, uma vez que é nesse processo que os sujeitos se manterão atualizados em relação a sua área de atuação, buscando desenvolver uma práxis reflexiva e responsiva. Em se tratando das novas modalidades de ensino, é sabido que muito se tem publicado a respeito da $\mathrm{FC}$ no âmbito da $\mathrm{EaD}$, no entanto, ainda se apresenta um fosso no que se refere a mediação, em um processo colaborativo, entre tutor/professor, ambiente virtual de aprendizagem e aluno. É aí em que entra a FC, oferecendo a oportunidade de os sujeitos levantarem, confrontarem, refletirem e (re)construírem sua atuação.

Ao direcionar o olhar para a $\mathrm{FC}$ do tutor em $\mathrm{EaD}$, é necessário destacar o que se entende por FC. Desse modo, recorrendo a Alarcão (1998), tem-se a definição que,

A formação continuada deve visar ao desenvolvimento das potencialidades profissionais de cada um, a que não é alheio ao desenvolvimento de si próprio como pessoa. Ocorrendo na continuidade da formação inicial, deve desenrolar-se em estreita ligação com o desempenho da prática educativa (ALARCÃO, 1998, p. 106).

De acordo com a pesquisadora, a FC é entendida como um processo contínuo, decorrente da formação inicial, tendo em vista que busca despertar no profissional o entendimento de que a graduação é apenas uma etapa de formação e que é necessário estar em constante aperfeiçoamento. Em consonância a essa definição, Esteves e Rodrigues (1993) discorrem que a FC

[...] tem lugar ao longo da carreira profissional após a aquisição da certificação profissional inicial (a qual só tem lugar após a conclusão da formação em serviço), 
privilegiando a ideia de que a sua inserção na carreira docente é qualitativamente diferenciada em relação à formação inicial, independentemente do momento e do tempo de serviço docente que o professor já possui quando faz a sua profissionalização, a qual consideramos ainda como uma etapa de formação inicial (ESTEVES E RODRIGUES, 1993, p. 44).

Para as autoras, independente do tempo de atuação do docente, é de sua importância que o mesmo invista em seu aperfeiçoamento, acompanhando as mudanças e avanços educacionais, confrontando-os, a fim de que os reflexos dessa formação impliquem no seu exercício de docência.

É nesse sentido que o trabalho do tutor em $\mathrm{EaD}$ deve ser guiado, haja vista que em ambientes virtuais de aprendizagem também ocorre a interação, desse modo, há troca de informações, o que possibilita ao professor e ao aluno, crescerem conjuntamente de forma colaborativa.

Costa-Hübes (2008) salienta em relação à FC, que

[...] o processo de aperfeiçoamento contínuo, redimensionando o conhecimento, necessita ser tratado como elemento constitutivo da formação de professores, sem desconsiderar que esta se dá, também, em outros tempos e espaços diferentes destes, uma vez que envolve sujeitos sócio-historicamente determinados (COSTA-HÜBES, 2008, p. 23).

A partir desse posicionamento da autora, pode-se refletir que a formação do docente, dá-se de forma contínua, em diferentes tempos e espaços, envolvendo sujeitos que se constituem historicamente.

Nas palavras de Fávero (1981) tem-se que,

[...] a formação do professor não se concretiza de uma só vez, é um processo. Não se produz apenas no interior de um grupo, nem se faz através de um curso, é o resultado de condições históricas. Faz parte necessária e intrínseca de uma realidade concreta determinada. Realidade essa que não pode ser tomada como uma coisa pronta, acabada, ou que se repete indefinidamente. É uma realidade que se faz no cotidiano. É um processo e como tal precisa ser pensado (FÁVERO, 1981, p. 17). 
Vol.11 - №19 - JANEIRO - 2019 - ISSN: 1982-6109

Fávero demonstra ser necessário garantir ao professor subsídios para que possa exercer seu trabalho com segurança, neste caso, na modalidade de ensino à distância. Desse modo, a FC surge como uma possibilidade de levar em conta as demandas dos tutores, a fim de que se possa contribuir para melhoria da qualidade de ensino.

A partir das questões levantadas pelos autores destacados acima, surgem alguns questionamentos: Qual o papel do tutor? Por que o trabalho do tutor é tão importante no EaD?

\section{O PAPEL DO TUTOR COMO PROFESSOR COLABORADOR VIRTUAL}

Com o advento tecnológico as novas modalidades de ensino se consolidaram. Tendo em vista a pulverização da EaD no Brasil e, considerando a gama universidades federais, estaduais e particulares investindo neste campo, esses avanços implicaram na demanda de um novo profissional para atuar nos AVA, o professor tutor.

No que se refere ao papel do tutor, Giannasiet al (2005) apresentam a atividade de tutoria como uma tarefa complexa, a qual exige do docente distintas habilidades para o desenvolvimento da função, dentre elas, os autores citam: competências técnicas, pedagógicas, comunicacionais, de iniciativa e criatividade, gerenciais, sociais e profissionais.

Ao partir desses critérios, percebe-se que o papel do tutor é decisivo no andamento do curso a distância, uma vez que é o recurso humano mais próximo do aluno. Sua atuação é decisiva para promoção do aprendizado, pois é ele quem auxilia na mediação pedagógica nos AVA.

Em afirmação, Martins (2002) aponta que,

No sistema de EaD, o tutor tem um papel relevante, pois é através dele que se garante a inter-relação personalizada e continua do estudante no sistema e se realiza a articulação necessária entre os elementos do processo e a consecução dos objetivos. (MARTINS, 2002. p. 31). 
Conforme Martins (2002), para que o papel que o tutor desempenha se efetive, é inegável que o mesmo receba uma formação adequada para o desenvolvimento de suas atividades. No entanto, observando os editais de seleção de tutores de universidades federais, estatuais e particulares, quase que predominantemente, os requisitos para o pleito das vagas não exigem, exclusivamente, formação especifica para o ensino na modalidade à distância. Reflexo dessa carência formativa são as dificuldades que esses docentes encontram no exercício de suas funções, para garantir com que o processo de aprendizado se efetive por meio de um ambiente virtual de aprendizagem, o que implica em evasão, dificuldades de aprendizado, além de críticas à modalidade de ensino.

Uma vez que o profissional atuante neste campo de ensino não possua formação especifica em $\mathrm{EaD}$, faz-se necessário garantir esse conhecimento em um processo de $\mathrm{FC}$, no caso do recorte deste trabalho, aos tutores, tendo em vista a complexidade e a responsabilidade atribuída à função que desempenham. Ademais, destaca-se que o despreparo dos profissionais expressa à despreocupação das políticas educacionais brasileiras, no que concerne a garantia do acesso à educação de qualidade oferecida pelas instituições credenciadas, tento em vista que para promoção integral e efetiva da $\mathrm{EaD}$, o passo inicial é investir na qualificação dos docentes.

Nas palavras de Aretio (1996), no que se refere às competências do tutor, o autor nos diz que,

O professor-tutor realiza uma contribuição especial ao aluno diante do desenvolvimento dos conteúdos de estudo: de um lado, ajuda e facilita na compreensão da matéria de estudo; e por outro, assessora e orienta no uso de estratégias e recursos de aprendizagem para incrementar suas destrezas no estudo independente (ARETIO, 1996. 264).

À vista disso, o papel tutor em uma abordagem colaborativa, interacionista, é de dialogar com seu interlocutor/aluno, por meio do suporte AVA, a fim de que se promova, por meio dessa interação, a efetivação do aprendizado. É válido reiterar, que segundo Villardi 
Vol.11 - №19 - JANEIRO - 2019 - ISSN: 1982-6109

(2005) "a questão da tutoria é, nesse momento, uma das mais relevantes a ser estudada e abordada, uma vez que a observação de alguns processos de formação via $\mathrm{EaD}$, vem apontando a atuação do tutor como decisiva para o sucesso da iniciativa e permanência do aluno até o final do curso" (2005, p. 440).

Conforme apresenta Villardi (2005), o tutor é a peça-chave na engrenagem da EaD, conforme apresentado no esquema abaixo:

Figura 1 - Esquema de aprendizagem em EaD.

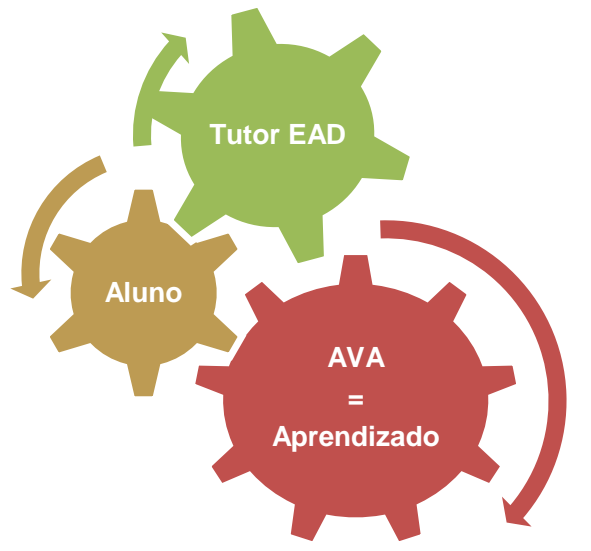

FONTE: Elaborado pelo autor.

Desse modo, a partir das reflexões em foco e da importância do papel de tutoria neste contexto de ensino, sinaliza-se a necessidade do tutor possuir formação condizente com a função que ocupa, uma vez que auxilia na promoção da qualidade e garantia do ensino prestado, sendo que, após a sua imersão enquanto profissional da área também deve investir em sua formação.

Conforme apresenta Ranguetti e Gesser (2004, p. 8-27) "para fazer frente a essas novas formas de ensinar, o professor passará a ter a necessidade constante de atualização, 
Vol.11 - №19 - JANEIRO - 2019 - ISSN: 1982-6109

tanto no que se refere ao seu conteúdo de ensino quanto em relação às novas metodologias de ensino e às novas tecnologias", sendo assim, o docente precisa estar disposto a enfrentar os novos desafios da educação, a fim de que possa (res)significar sua prática na medida em que as transformações da sociedade tragam essa exigência.

\section{A MEDIAÇÃo PEGAGÓgICA EM AMBIENTES VIRTUAIS DE APRENDIZAGEM: A COLABORAÇÃO EM FOCO}

Os Ambientes Virtuais de Aprendizagem (AVA) são espaços essenciais para que o processo de ensino na modalidade de EaD possa ocorrer. Nesse espaço o tutor desenvolve suas funções de forma colaborativa, por isso, é necessário que tenha clareza e domínio da sua plataforma de atuação.

Sendo o AVA um espaço de interação e colaboração, faz-se necessário apresentar como ocorre esse processo. Recorrendo a Magalhães (2004) tem-se que,

Colaborar, em qualquer contexto (pesquisa, formação contínua, sala de aula), significa agir no sentido de possibilitar que os agentes participantes tornem seus processos mentais claros, expliquem, demonstrem, com o objetivo de criar, para os outros participantes, possibilidades de questionar, expandir, recolocar o que foi posto em negociação (MAGALHÃES, 2004, p. 76).

Nesse contexto, o tutor tem a possibilidade de trazer o aluno para o centro do processo de ensino-aprendizagem, uma vez que por meio da interação, em um via de mão dupla, irá refletir conjuntamente com o aluno, mediando, confrontando, (res)significando e construindo conhecimento. À luz das reflexões de Magalhães (2004), pode-se compreender que em um processo colaborativo tanto tutor quanto o aluno poderão clarificar seus processos mentais em busca do conhecimento, conforme explicitado na figura abaixo: 
Vol.11 - №19 - JANEIRO - 2019 - ISSN: 1982-6109

Figura 2 - Processo colaborativo de aprendizado em EaD.

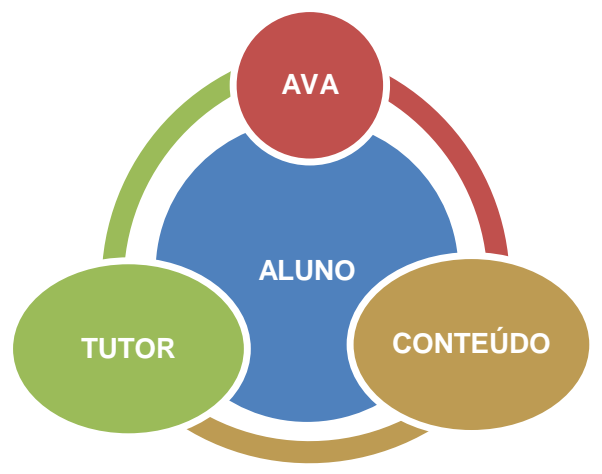

Fonte: Elaborado pelo pesquisador.

Como apresentado no esquema acima, em um sistema de educação à distância o aluno está no centro do processo de ensino e, por meio da interação e colaboração que ocorre com a mediação do tutor, no ambiente virtual de aprendizagem, ocorre à produção do conhecimento, consequentemente, a clarificação dos conteúdos. Desse modo, é basilar que o tutor esteja atento ao suporte de mediação de aprendizagem, a fim de que explore todos os recursos com vistas à efetivação do aprendizado do aluno.

Mas afinal, o que é AVA? O AVA é uma plataforma online que auxilia, por meio da internet, o processo de interação e mediação do ensino na modalidade EaD. É nessa plataforma que professor/aluno/conteúdo interagem e que se constrói conhecimento. Entre os objetivos do AVA, podem-se citar os seguintes, oportunizar o exercício de novas práticas educacionais; propiciar a interação entre os participantes nesse contexto de ensino; servir como um canal de pesquisa, além de, possibilitar a troca de experiências.

Dentre os benefícios que a utilização dos AVA propicia, destacam-se: a superação do tempo e do espaço em que ocorrem as atividades de ensino-aprendizagem; conteúdos interativos; a agilidade na comunicação entre os diversos setores que envolvem a EaD; além 
Vol.11 - №19 - JANEIRO - 2019 - ISSN: 1982-6109

da interação que ocorre por meio de diversos canais de comunicação coletiva, como fóruns e abas de debates sobre os conteúdos estudados pelo discente.

É por meio dessa plataforma que o aluno terá acesso a inúmeros recursos disponibilizados pelo professor da disciplina do curso em questão, dentre eles, destacam-se alguns no quadro que segue:

\section{Quadro 1 - Recursos dos Ambientes Virtuais de Aprendizagem.}

\begin{tabular}{|c|}
\hline RECURSOS DO AVA \\
\hline - Download de materiais. \\
- Vídeo aulas. \\
- Calendário acadêmico. \\
- Resultados de avaliações. \\
- Interação com o tutor/aluno e \\
aluno/tutor. \\
- Realização de atividades. \\
- Participação em fóruns e chats. \\
\hline
\end{tabular}

Fonte: Adaptado de Nater (2016).

Desse modo, nesse contexto de aprendizagem virtual, para que a mediação colaborativa ocorra, é primordial que se apliquem estratégias de ensino-aprendizagem, a fim de que a presença física do professor seja suprida. Sendo assim, os ambientes virtuais de aprendizagem devem servir para estimular o aluno a desenvolver autonomia em sua prática de estudo e incentivá-lo a dialogar nos campos específicos, com os tutores, professores, colegas, entre outros, com o objetivo de que a construção do saber se dê de forma criativa, dialogada, construtiva e colaborativa.

Em consonância com Demo (1998), no que se refere ao entendimento dos espaços de aprendizagem como meios de interação, o autor traz em evidência, que os suportes servem apenas para mediação e não substituem a figura do tutor, do professor, tendo em vista que são 
Vol.11 - №19 - JANEIRO - 2019 - ISSN: 1982-6109

sujeitos essenciais para que a mediação do conteúdo, interação e construção do conhecimento ocorra. Ressaltado esse aspecto, Demo diz que,

Decorreria desta constatação que a instrumentação eletrônica detém significado talvez insuperável no campo da informação disponível, por conta da capacidade de memória, processamento, etc., mas não garante, por si, o processo formativo essencial na aprendizagem autêntica. Se quiséssemos fazer um contraponto, os meios eletrônicos resolvem bem o horizonte da informação, mas não têm o poder de resolver, por si sós, o da formação. (DEMO, 1998, p.188).

Portanto, precisa-se compreender que nesse campo de ensino, os ambientes de aprendizagem são primordiais, no entanto, por si sós, como mencionado pelo autor, não suprem a necessidade de interação e mediação que o estudante tem. Desse modo, faz-se necessária a colaboração do tutor.

\section{CONSIDERAÇÕES FINAIS}

A partir de todo o percurso apresentado neste artigo, fica evidente que com a expansão da oferta de ensino na modalidade $\mathrm{EaD}$, surge a necessidade de se pensar no papel dos membros que conduzem esse trabalho, na busca de oferecer uma educação de qualidade em tempos e espaços diferentes.

À vista disso, esse trabalho se propôs a refletir sobre a formação continuada de tutores, para mediação colaborativa do conhecimento, em ambientes virtuais de aprendizagem, tendo em vista a complexidade da função de tutoria, função essa, que é peça-chave na engrenagem da $\mathrm{EaD}$.

Destaca-se que a tutoria exige do profissional um olhar atento às demandas do seu campo de atuação, sendo necessário encontrar subsídios para orientar e instigar o estudante de $\mathrm{EaD}$ a ser um sujeito autônomo e ser ativo em seu processo de aprendizagem. Daí, a importância da formação continuada, uma vez que se torna o tempo e espaço para o diálogo 
Vol.11 - №19 - JANEIRO - 2019 - ISSN: 1982-6109

colaborativo, confrontos teóricos e a troca de experiências. O tutor, integrante de um conjunto de profissionais imersos neste contexto educacional, desenvolve um trabalho de grande valia para formação à distância, desse modo, faz-se necessário que possua uma formação sólida para o trabalho sob uma perspectiva dialógica, colaborativa, estando em contínuo aperfeiçoamento, compreendendo que a formação continuada é um processo ininterrupto, conforme destaca Alarcão (1998) e Costa-Hübes (2008).

Neste sentido, o tutor deve compreender esse processo como permanente, haja vista que para cada contexto, cada momento histórico, há a necessidade de adaptar-se, a fim de que sua prática esteja em consonância com seu campo de atuação do presente, bem como, com os documentos norteadores da educação.

Destarte, por se tratar do recurso humano mais próximo do aluno, deve estar preparado para mediar os impasses que surgirem durante o período de estudo, uma vez que, quando o aluno não consegue estreitar os laços com a instituição, bem como, com os mediadores, acaba evadindo, competindo ao tutor, também, estimular a permanência discente.

Ademais, é necessário que os órgãos governamentais garantam por meio de políticas públicas, que se efetivem na prática, a formação basilar para os professores que atuam no contexto da $\mathrm{EaD}$, a fim de que essa modalidade de ensino continue na busca por garantir uma formação adequada aos alunos.

\section{REFERÊNCIAS}

ALARCÃO, Isabel. Formação continuada como instrumento de profissionalização docente. In.: VEIGA, I. P. A. (org.) Caminhos da profissionalização do magistério. Campinas, SP: Papirus, 1998.

ARETIO, Lorenzo Garcia. La educación a distancia y la UNED.Madrid: UNED, 1996.

BRASIL. Decreto no 2.494/98. Revogado pelo Decreto no 5.622, de 2005. Disponível em: http://www.planalto.gov.br/ccivil_03/decreto/D2494.htm. Acesso em 10 de junho de 2015. 
Vol.11 - №19 - JANEIRO - 2019 - ISSN: 1982-6109

Decreto no 5.622 de 19 de dezembro de 2005. Regulamenta o art. 80 da Lei $n^{\circ}$

9.394, de 20 de dezembro de 1996 (LDB). Disponível em:

http://www.planalto.gov.br/ccivil_03/_Ato2004-2006/2005/Decreto/D5622.htm. Acesso em 10 de junho de 2015.

Decreto 5.773 de junho de 2006. Disponível em:

http://portal.mec.gov.br/seed/arquivos/pdf/legislacao/decreton57731.pdf. Acesso em 10 de junho de 2015.

Portarias Normativas 1 de 10 de janeiro de 2007. Disponível em:

http://portal.mec.gov.br/seed/arquivos/pdf/legislacao/portaria1.pdf. Acesso em 10 de junho de 2015. BRASIL. MEC/SEED. Referenciais de Qualidade em EAD. 2007. Disponível em: http://portal.mec.gov.br/seed/arquivos/pdf/legislacao/refead1.pdf. Acesso em 10 de junho de 2015.

Ministério da Educação. Lei de Diretrizes e Bases da Educação de 20 de dezembro de 1996. Diário Oficial da União, Brasília, 23 de dezembro de 1996. Disponível em: http://www.planalto.gov.br/ccivil_03/Leis/L9394.htm. Acesso em 10 de junho de 2015.

Decreto $n^{0}$ 9.057, de 25 de maio de 2017. Disponível em:

http://www.planalto.gov.br/ccivil_03/_Ato2015-2018/2017/Decreto/D9057.htm\#art24. Acesso em 18 de novembro de 2018.

COSTA-HÜBES, Terezinha da Conceição. O processo de formação continuada dos professores do Oeste do Paraná: um resgate histórico-reflexivo da formação em Língua Portuguesa. Londrina, 2008, 308 f.Tese (Doutorado em Estudos da Linguagem) - Programa de Pós-graduação Stricto Sensu em Estudos da Linguagem, Universidade Estadual de Londrina, Londrina - PR, 2008.

DEMO, Pedro. A pesquisa como princípio educativo na universidade. In: Pesquisa em sala de aula: tendências para a educação em novos tempos. MORAES, Roque, e LIMA, Valderez Marina do Rosário.ogs. Porto Alegre. EDIPUCRS. 2004.

Questões para a teleducação. Petrópolis. Vozes. 1998.

FÁVERO, M. de L. A formação do educador: desafios e perspectivas. Série estudos. Rio de Janeiro: PUC/RJ, 1981.

GIANNASI, Maria Júlia et al. A prática pedagógica do tutor no ensino a distância: resultados preliminares. Virtual Educa 2005, México, 2005.

MAGALHÃES, Maria Cecília Camargo. A linguagem na formação de professores reflexivos e críticos. In: (Org). A formação do professor como um profissional crítico: linguagem e reflexão. Campinas, Mercado das Letras, 2004. p. 59-117. 
Vol.11 - №19 - JANEIRO - 2019 - ISSN: 1982-6109

MARTINS, Onilza Borges. A educação superior à distância e a democratização do saber. Petrópolis: Vozes, 1991.

Teoria e Prática Tutorial em Educação a Distância. Curitiba: IBPEX, 2002.

RANGUETTI, V. GESSER, D. S.. O Currículo no ensino superior: princípios epistemológicos para um design contemporâneo. Pontifícia Universidade Católica de São Paulo Programa de Pós-graduação Educação: Currículo. Revista e-curriculum ISSN: 18093876.

RODRIGUES, Ângela; ESTEVES, Manuela. A análise de necessidades na formação de professores. Col. Ciências da Educação. Porto: Portugal, 1993.

VILLARDI, Raquel. Tecnologia na educação: uma perspectiva sócio- interacionista/ Raquel Villardi e Eloiza Gomes de Oliveira. Rio de Janeiro: Dunya, 2005. 
Vol.11 - №19 - JANEIRO - 2019 - ISSN: 1982-6109

\section{João Carlos Rossi}

Especialista em Educação Especial e em Educação a Distância com ênfase na formação de tutores. Mestrando em Letras, no Programa de Pós-graduação Stricto Sensu em Letras, pela Universidade Estadual do Oeste do Paraná - UNIOESTE Campus Cascavel. Professor do Centro de Ensino Superior de Realeza - CESREAL.

Artigo recebido em 22/11/2018

Aceito para publicação em 29/01/2019

Para citar este trabalho:

ROSSI, João Carlos. AÇÕES COLABORATIVAS EM AMBIENTES VIRTUAIS DE APRENDIZAGEM: UMA REFLEXÃO SOBRE A FORMAÇÃo CONTINUAdA DE TUTORES. Revista Paidéi@. Unimes Virtual. Volume 11- Número 19 - JANEIRO - 2019 - Disponível em:

http://periodicos.unimesvirtual.com.br/index.php?journal=paideia\&page=index 